\title{
Mortalité de l'huître Crassostrea gigas dans le bassin de Marennes-Oléron : étude de la variabilité spatiale de son environnement et de sa biologie par un système d'informations géographiques (SIG)
}

\author{
Patrick Soletchnik ${ }^{(*)}$, Olivier Le Moine, Nicole Faury, \\ Daniel Razet, Philippe Geairon, Philippe Goulletquer
}

Laboratoire conchylicole de Poitou-Charentes, Ifremer, BP 133, 17390 La Tremblade, France.

Reçu le 4 novembre 1998 ; accepté le 19 janvier 1999.

\begin{abstract}
Summer mortality of the oyster in the Bay Marennes-Oléron: Spatial variability of environment and biology using a geographical information system (GIS). The summer mortality patterns was studied in 1996 on the Ronce-les-Bains oyster bank (175 ha), located on the southern part of the Bay Marennes-Oléron (Atlantic coastline). Studies on growth, sexual maturation, survival rates and environmental variables were compared at fifteen experimental sites (on- and off-bottom culture). After 7 months, cumulative mortality reached 8-19 and 23-33\% for off-bottom and on-bottom culture, respectively, which is significantly higher for the latter case. A seasonal mortality trend was noted, with a significant increase related to air temperature greater than $20^{\circ} \mathrm{C}$ and with a significant pre-spawning glycogen catabolism. Based on soft tissue flesh growth results from both types of culture, several empirical models were developed to assess overall yield from a spatial point of view. A N-NW positive trend was noted for the soft tissue flesh, suggesting a decrease in food availability towards the southern part of the bay. Yields (total weight) ranged from 85 to $2 \%$ for otf-bottom cultures with 25 and $50 \%$ emersion times, respectively. For on-bottom culture, several sites have shown a negative yield down to $-10 \%$ in the southern oyster bank sites. The highest yields were noted in areas located on the E-NE part of the Ronce oyster bank. (c) Ifremer/Cnrs/Inra/Ird/Cemagref/Elsevier, Paris
\end{abstract}

Growth rates / mortality / Crassostrea gigas / Atlantic ocean

Résumé - Le banc ostréicole de Ronce ( 175 ha) au sud du bassin de Marennes-Oléron (France) constitue un site atelier expérimental pour l'étude des mortalités estivales de l'huître creuse Crassostrea gigas. En 1997, la croissance, la maturité sexuelle, la survie et l'environnement des élevages à plat et sur tables sont comparés sur quinze sites expérimentaux. En 7 mois, le taux de mortalité des élevages à plat atteint 23-33\% contre 8-19\% pour les élevages sur tables. La mortalité varie avec la saison. Elle s'intensifie avec la température, en période de pré-ponte et de catabolisme du glycogène. Des modèles statistiques de production de chair sèche de l'huître sont établis selon la latitude et la longitude des sites. Ces modèles (en poids sec) sont orientés nord - nordouest et montrent que la disponibilité alimentaire pour les cheptels d'huîtres, diminue progressivement du large vers le fond de la baie. Les rendements biologiques (poids total), sont compris entre 85 et $2 \%$, respectivement pour des sites sur tables à 25 et $50 \%$ d'exondation. Pour les élevages à plat, une perte de production supérieure à $10 \%$ est enregistréc dans certains parcs du sud du bassin. Les meilleurs sites, à $50 \%$ de production (poids total), sont situés dans la partie est - nord-est du banc de Ronce. (O Ifremer/ Cnrs/Inra/Ird/Cemagref/Elsevier, Paris

Croissance / mortalité / Crassostrea gigas / océan Atlantique

\section{INTRODUCTION}

L'huître creuse, Crassostrea gigas a été introduite en France en 1967 [13]. Sur la côte Atlantique, le bassin de Marennes-Oléron (figure $l$ ) est le premier bassin ostréicole européen avec un stock d'huîtres creuses (Crassostrea gigas) de 110000 tonnes pour une pro- duction annuelle de 30000 à 40000 tonnes. Le banc ostréicole de Ronce, au sud du bassin (figure l), est formé de 1600 concessions réparties sur 175 ha. Il produit 8000 à 10000 tonnes d'huîtres creuses par an.

L'élevage de Crassostrea gigas est pratiqué depuis plus de 1000 ans au Japon [9]. Depuis le début des années 1960, des épisodes de mortalité d'huîtres se

* Auteur correspondant, e-mail: Patrick.Soletchnik@ifremer.fr 


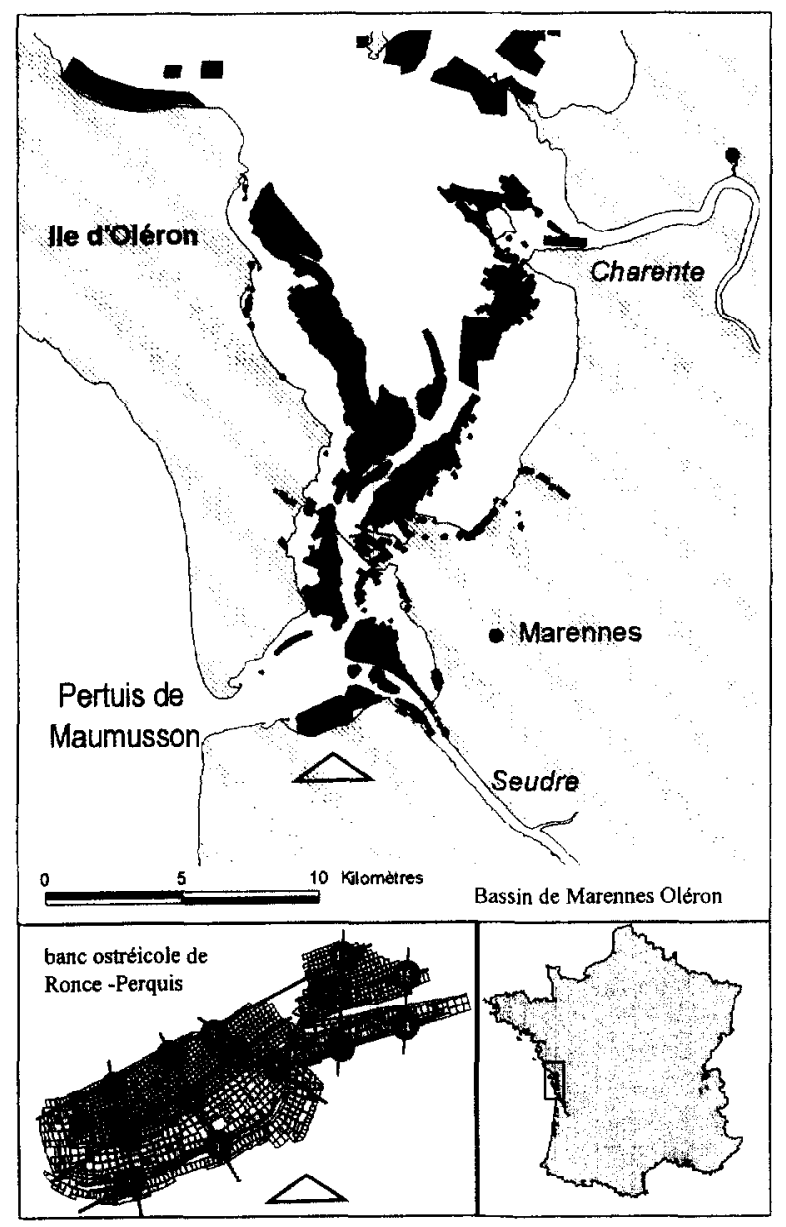

Figure 1. Sites ostréicoles expérimentaux du banc de Konce-les-Bains dans le sud du bassin de Marennes-Oléron (France).

Figure 1. Experimental sites on the Ronce-Les-Bains oyster bank in the southern part of the Marennes-Oleron bay (France).

sont multipliés dans le monde $[5,9,18,23,35]$. Le Japon et la côte Ouest des États-Unis en particulier ont connu dans les années 1960 et 1970 des mortalités estivales détruisant jusqu'à $60 \%$ des cheptels de $C$. gigas $[11,19]$. Ces mortalités ont été considérées comme le phénomène biologique le plus important de la première moitié du $20^{\mathrm{e}}$ siècle [14]. Si certaines mortalités sont clairement identifiées comme étant d'origine pathogène [5,9], d'autres mortalités peuvent survenir à l'occasion d'épisodes climatiques exceptionnels [23]. De nombreux cas de mortalité sont encore souvent classés comme «d'origine inconnue ».

En France, des mortalités importantes (15-30\%) apparaissent depuis le début des années 1980 sur divers sites ostréicoles (e.g. Pen Bé en Bretagne Sud, le bassin d'Arcachon [26]). Dans le bassin de MarennesOléron, des mortalités estivales se manifestent également de façon chronique ou à l'occasion de crises importantes (mai 1988 [6]. juin 1993). Les élevages « à plat » sont les plus sensibles à ces mortalités. Une des causes serait le possible enrichissement en matière organique de l'interface eau-sédiment, résultant du manque de circulation des eaux, des rejets du réseau pluvial et de l'absence d'enlèvement des anciennes installations ostréicoles [25,38]. Jusqu'à présent, les tests relatifs à la qualité des eaux impliquant une toxicité naturelle phytoplanctonique ou industrielle sont systématiquement négatifs [6]. L'hypothèse d'une cause infectieuse n'a jamais été démontrée malgré le suivi pathologique par un laboratoire spécialisé.

L'étude de la capacité trophique du bassin de Marennes-Oléron est un sujet largement abordé $[2-4,7,32]$. L'insuffisance des réserves trophiques peut être suspectée. La modélisation des capacités trophiques a été mise en relation avec des chutes de production dans le bassin de Marennes-Oléron. Ces modèles n'ont pas permis d'expliquer les mortalités ponctuelles malgré l'allongement des temps de croissance et une augmentation des morlalités chroniques [17]. Qu'en est-il dans le cas de cette étude?

Les huîtres distribuées sur la frange côtière, le plus souvent dans la zone intertidale et estuarienne, sont naturellement habituées à supporter de fortes variations de température et de salinité. Toutefois, ces zones sont soumises à des pressions anthropiques de plus en plus fortes $[15,27,28,37]$ et les causes de mortalité « suspectées » de nature «environnementale », sont de plus en plus fréquentes. Des changements physico-chimiques dans l'environnement estuarien peuvent avoir pour conséquence des mortalités massives, impliquant des aires géographiques restreintes (e.g. embouchure d'une rivière) [30]. Plus récemment, des perturbations environnementales ont été jugées responsables de mortalités d'huîtres creuses au cours de phénomènes d'eutrophisation [29]. Qu'en est-il pour le bassin de Marennes-Oléron? Les mortalités estivales de l'huître creuse Crassostrea gigas constituent-elles une alarme de la situation environnementale de ce bassin?

Le banc de Ronce dans le sud du bassin de Marennes-Oléron (figure I) a été choisi comme site atelier depuis 1995. En 1996, la démarche est globale et multifactorielle. Biométrie, mortalité, pratiques culturales et environnement (température, salinité, oxygène, $\mathrm{pH}$ ) sont pris en compte dans l'étude. Elle montre que l'état physiologique initial des huitres et l'origine des lots conditionnent peu l'apparition des mortalités. Le taux de mortalité est supérieur pour les élevages « à plat » [21].

Le programme conduit en 1997 aborde les questions suivantes. Existe-t-il une relation entre la mortalité et la qualité sédimentaire des sites d'élevage? Comment la mortalité évolue-t-elle au cours du temps ? Quelles sont les performances de croissance des cheptels dans le sud du bassin de MarennesOléron? Les résultats reflètent-ils une réelle limitation trophique dans cette zone du bassin ? 


\section{MATÉRIEL ET MÉTHODES}

\subsection{Les sites expérimentaux}

Les sites ateliers sont aménagés sur des parcs ostréicoles professionnels sur le banc de Ronce dans le sud du bassin de Marennes-Oléron (France) (figure 1). Une population homogène d'huîtres de 3 ans a été mise en place simultanément sur les quinze sites expérimentaux selon trois radiales est-ouest et cinq radiales nordsud et à différentes altitudes. Chaque site comprend un parc de $10 \mathrm{~m}^{2}$ avec $100 \mathrm{~kg}$ d'huîtres « à plat » et une table ostréicole avec deux poches de 200 huîtres «sur tables ". Ce sont les deux modalités du descripteur " type d'élevage ». Les élevages à plat ne peuvent être réalisés sur les sites $3,6,9,10$ et 12 , trop exposés aux courants de marée. Les sites sont positionnés dans l'espace selon leurs coordonnées géographiques de latitude $(x)$ et de longitude $(y)$ en projection Lambert II et en altitude par rapport au niveau de plus basse mer (z) (tableau I). Ainsi, l'altitude des parcs expérimen-

Tableau I. Les descripteurs de l'étude pour les deux types d'élevage : huîtres " à plat » sur le sol et " sur tables " ostréicoles à $50 \mathrm{~cm}$ de hauteur.

Table 1. Descriptive elements of the study for the two types of oyster culture: on-and off-bottom cultures.

\begin{tabular}{|c|c|c|}
\hline Symbole & Définition & Unité \\
\hline$x, y$ & $\begin{array}{l}\text { Coordonnées géographiques } \\
\text { en latitude }(x) \text { et en longitude }(y) \\
\text { des sites expérimentaux; projection } \\
\text { géographique en coordonnées } \\
\text { Lambert }\end{array}$ & $\mathrm{m}$ \\
\hline$z$ & $\begin{array}{l}\text { Altitude des sites expérimentaux par } \\
\text { rapport au zéro des cartes marines }\end{array}$ & $\mathrm{m}$ \\
\hline$T_{\mathrm{imm}}$ & Temps d'immersion & $\mathscr{m}$ \\
\hline mort & $\begin{array}{l}\text { Mortalité cumulée sur l'ensemble } \\
\text { de la période }\end{array}$ & $\%$ \\
\hline$t_{\text {mort }}$ & Taux de mortalité journalière & $\% \cdot j^{-1}$ \\
\hline$P t$ & Poids total & g \\
\hline$P c$ & Poids de coquille & $\mathrm{g}$ \\
\hline$P_{\mathrm{s}}$ & Poids sec & g \\
\hline ponte & $\begin{array}{l}\text { Effort de ponte estimé par la perte } \\
\text { de poids sec mesurée en été }\end{array}$ & S1 1 \\
\hline & Stades de maturité sexuelle & éch. relative (1) \\
\hline gly & Teneur en glycogène de la chair sèche & $\%$ \\
\hline glu & Teneur en glucides de la chair sèche & $\%$ \\
\hline lip & Teneur en lipides de la chair sèche & $\%$ \\
\hline$P r_{1}$ & Production en poids total & $\mathrm{mg} \cdot \mathrm{j}^{-1}$ \\
\hline $\operatorname{Pr}_{\mathrm{c}}$ & Production en poids de coquille & $\mathrm{mg} \cdot \mathrm{j}^{-1}$ \\
\hline$P_{r_{\mathrm{s}}}$ & Production en soma & $\mathrm{mg} \cdot \mathrm{j}^{-1}$ \\
\hline $\operatorname{Pr}_{\mathrm{g}}$ & Production de gamètes & $\mathrm{mg} \cdot \mathrm{j}^{-1}$ \\
\hline $\mathrm{rdt}$ & Rendement biologique & $\%$ \\
\hline carb & $\begin{array}{l}\text { Teneur en carbone du sédiment sec } \\
\text { superficiel }\end{array}$ & $\mu \mathrm{g} \cdot \mathrm{mg}^{-1}$ \\
\hline sal & $\begin{array}{l}\text { Salinité de l'eau interstitielle } \\
\text { du sédiment superficiel }\end{array}$ & \\
\hline $\mathrm{NH}_{4}^{+}$ & Teneur en azote ammoniacal & $\mu \mathrm{mol} \times \mathrm{L}^{-1}$ \\
\hline coli & Teneur en coliformes fécaux & éch. relative (2) \\
\hline stre & Teneur en streptocoques fécaux & éch. relative (2) \\
\hline
\end{tabular}

(1) Échelle relative de maturité sexuelle [36].

(2) Échelle relative de contamination : 1, inférieur au seuil de détection; 2 , peu contaminé; 3 , légèrement contaminé; 4 , contaminé; 5 , fortement contaminé.

Aquat. Ljving Resour. 12 (2) (1999) taux est comprise entre 1,6 et $3,6 \mathrm{~m}$ et leur taux d'émersion se situe entre 16 et $54 \%$ (tableau II).

\section{2. Échantillonnage et analyses}

La fréquence d'échantillonnage entre le 25 mars et le 15 octobre 1997 (début et fin d'expérimentation) est de 12 pour la mortalité et de 8 pour les mesures de biométrie. L'échantillonnage consiste en un prélèvement mensuel de 30 huîtres en poche (élevage sur tables) et dans les parcs expérimentaux. Les mesures de mortalité sont effectuées par l'intermédiaire d'un "cadrat " d'échantillonnage (élevages à " plat ") ou par comptage dans une poche de 200 huîtres (élevage sur tables) tous les $15 \mathrm{j}$. Les traitements effectués sur les huîtres sont les mesures du poids total (g), du poids sec $(\mathrm{g})$ après lyophilisation et du poids de coquille (g) (tableau I). Le stade de maturité sexuelle est apprécié selon une échelle relative faisant appel à des critères macroscopiques et microscopiques d'observation de la gonade et des gamètes [36]. L'effort de ponte est estimé par la perte de poids sec (g) enregistrée entre le 21 juillet et le 18 août $[22,12]$. Le glycogène est analysé par dosage spectrophotométrique [33].

Les productions en poids total $\left(P r_{t}\right)$ et en coquille $\left(P r_{\mathrm{c}}\right)$ sont calculées sur la période de $204 \mathrm{j}$ d'élevage (du 25 mars au 15 octobre) selon les formules :

$$
\begin{aligned}
& P r_{1}=\left(P t_{\text {final }}-P t_{\text {initial }}\right) / 204 \times 1000 \\
& P r_{\mathrm{c}}=\left(P \mathrm{c}_{\text {final }}-P \mathrm{c}_{\text {initial }}\right) / 204 \times 1000
\end{aligned}
$$

La production de soma et de gamètes $\left(P r_{s+g}\right)(5)$ est calculée comme la somme de production de soma en $204 \mathrm{j}$ (3) et de la production de gametes en $118 \mathrm{j}$ (du 25 mars au 21 juillet) (4).

$$
\begin{gathered}
P r_{\mathrm{s}}=\left(P \mathrm{~s}_{\text {final }}-P \mathrm{~s}_{\text {initial }}\right) / 204 \times 1000 \\
P r_{\mathrm{g}}=\text { ponte } / 118 \times 1000 \\
P r_{\mathrm{s}+\mathrm{g}}=P r_{\mathrm{s}}+P r_{\mathrm{g}}
\end{gathered}
$$

Le rendement biologique (rdt) (\%) est calculé selon la formule suivante :

$$
\mathrm{rdt}=\underset{\text { biomasse }_{\text {initiale }}}{\left(\text { biomasse }_{\text {inale }}-\text { biomasse }_{\text {initiale }}\right) /}
$$

où la biomasse est le produit du poids total individuel (g) par le taux de survie.

Un prélèvement de vase de $1 \mathrm{~L}$ est réalisé en surface du sédiment ( $2 \mathrm{~cm}$ d'épaisseur) sur chaque site. $\mathrm{Au}$ laboratoire, l'échantillon de vase est centrifugé $15 \mathrm{~min}$ à $4000 \times g$. La salinité de l'eau interstitielle est mesurée par la méthode chimique et sa teneur en azote ammoniacalc par colorimétrie spectrophotométrique. La teneur en carbone de la vase est mesurée grâce à l'analyseur thermique CHNS/O 2400. Les mesures bactériologiques sont effectuées par prélèvement d'un aliquote de sédiment dans un flacon stérile, sur chaque site. Au laboratoire, les teneurs en coliformes et strep- 
Tableau II. Les sites expérimentaux du banc de Ronce ; altitude (m) (par rapport au niveau zéro des cartes marines) et temps d'émersion (\%).

Table II. Experimental sites of the Ronce-Les-Bains oyster bank; altitude ( $m$ ) (from level ' $O$ ' of marine charts) and emersion time (\%).

\begin{tabular}{|c|c|c|c|c|c|c|c|c|c|c|c|c|c|c|c|c|}
\hline \multirow[t]{2}{*}{ Élevage } & & \multicolumn{15}{|c|}{ Code sites } \\
\hline & & 1 & 2 & 3 & 4 & 5 & 6 & 7 & 8 & 9 & 10 & 11 & 12 & 13 & 14 & 15 \\
\hline Table & Altitude (m) & 3,4 & 3,6 & 2,4 & 2,5 & 3,6 & 2.2 & 3,0 & 3,2 & 2,3 & 3,0 & 3,1 & 3,0 & 2,0 & 2,9 & 2,1 \\
\hline Table & Emersion $(\%)$ & 49 & 54 & 31 & 33 & 54 & 26 & 41 & 46 & 30 & 41 & 43 & 43 & 24 & 40 & 25 \\
\hline Plat & Altitude (m) & 3,1 & 3,4 & 1,9 & 2,4 & 3,1 & 1,6 & 2,8 & 2,7 & 2,0 & 2,7 & 2,9 & 2,5 & 1,8 & 2,7 & 1,8 \\
\hline Plat & Emersion (\%) & 44 & 50 & 21 & 31 & 44 & 16 & 38 & 37 & 23 & 37 & 40 & 33 & 20 & 37 & 20 \\
\hline
\end{tabular}

tocoques fécaux sont déterminées par des méthodes conformes aux normes Afnor.

\subsection{Analyse statistique}

Les analyses statistiques sont effectuées à l'aide du logicicl «Statgraphics plus » (version 3.1). La comparaison intersites pour les descripteurs environnementaux est analysée au moyen des tests de rang de Kruskal-Wallis. Les diagrammes en " boîte à moustaches » présentent la valeur centrale (médiane) et la dispersion des valeurs ; $50 \%$ des valeurs sont définies par la " boîte ", et la partie "moustaches » présente les valeurs minimales et maximales de la distribution. L'« encoche » de la «boîte " définit l'intervalle de confiance autour de la médiane (seuil de $95 \%$ ). La croissance est étudiée au moyen d'analyses de variance (Manova) selon les types d'élevage, les sites et l'interaction entre ces deux facteurs. Les analyses de variance sont effectuées sur les sites où sont représentés les deux types d'élevage (à plat et sur table) $(1,2,4$, $5,7,8,11,12,14,15)$. Des matrices de corrélation sont calculées entre les réponses biologiques et les descripteurs environnementaux. Les modèles de production sont obtenus par régressions multilinéaires. Le géo-référencement des productions sur le banc de Ronce est effectué au moyen du logiciel ArcView version, 3.0.

\section{RÉSULTATS}

\subsection{Mortalité et sites d'élevage}

Le taux de mortalité en fin d'élevage est de 23-33\% pour les élevages à plat et de 8-19\% pour les élevages sur table (figure 2), avec une médiane respective de 28 et $12 \%$ pour les deux types d'élevage. Au terme des 7 mois d'élevage, la mortalité la plus faible sur tables $(8 \%)$, se rencontre sur deux sites radicalement opposés au nord-ouest (site 3 ) et au sud-est (site 14) du banc de Ronce. À plat, la mortalité la plus faible (23\%), est celle du site 2 à l'ouest du banc de Ronce alors que ce site a la plus forte mortalité sur table (19\%).

Les descripteurs de la vase, la teneur en carbone (carb), la teneur en azote ammoniacale $\left(\mathrm{NH}_{4}^{+}\right)$et la salinité (sal) de l'eau interstitielle ainsi que la teneur en streptocoques et coliformes, sont des descripteurs caractéristiques du site et peu variables dans le temps

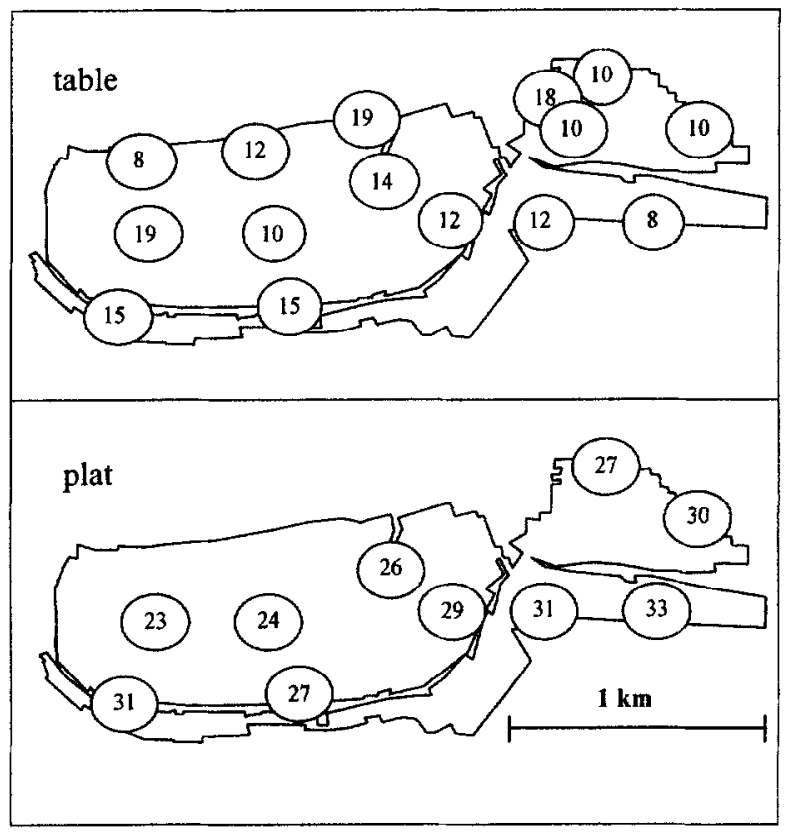

Figure 2. Représentation géographique des taux de mortalité cumulés (\%) de l'huître C. gigas après 7 mois d'élevage sur tables (A) et à plat (B).

Figure 2. Geographical representation of the cumulated mortality rate $(\%)$ of the oyster $C$. gigas after seven months off- $(A)$ and onbottom $(B)$ rearing.

(figure 3). Les sédiments des sites $1,4,7,8$ et 11 au sud - sud-ouest du banc (figure I) se caractérisent par une teneur en carbone proche de $25 \mu \mathrm{g} \cdot \mathrm{mg}^{-1}$ en opposition avec ceux du nord-ouest du banc dont la teneur en carbone est de $10-15 \mu \mathrm{g} \cdot \mathrm{mg}^{-1}$. La teneur en azote ammoniacale de l'eau interstitielle est de 20-50 $\mu \mathrm{mol}$ dans le sud-ouest du banc (sites 1, 2, 4 et 5). Elle est la plus forte sur les sites 3,6 et 9 les plus «profonds » au nord du banc. La salinité de l'eau interstitielle décroît sensiblement du sud-est du bassin vers le nord-ouest, de 36 à 34 (figure 3). Le site 9 se caractérise comme un site significativement plus "salé " (39). Le site 15 connaît de fortes fluctuations de salinité de 27 à 35 . Les sites sans coliformes fécaux $(1,2,4,9,10,12$ et $13)$ sont également les sites où la concentration en streptocoques est la plus faible $(2,4,9,10,12$ et 13) (figure 3). 

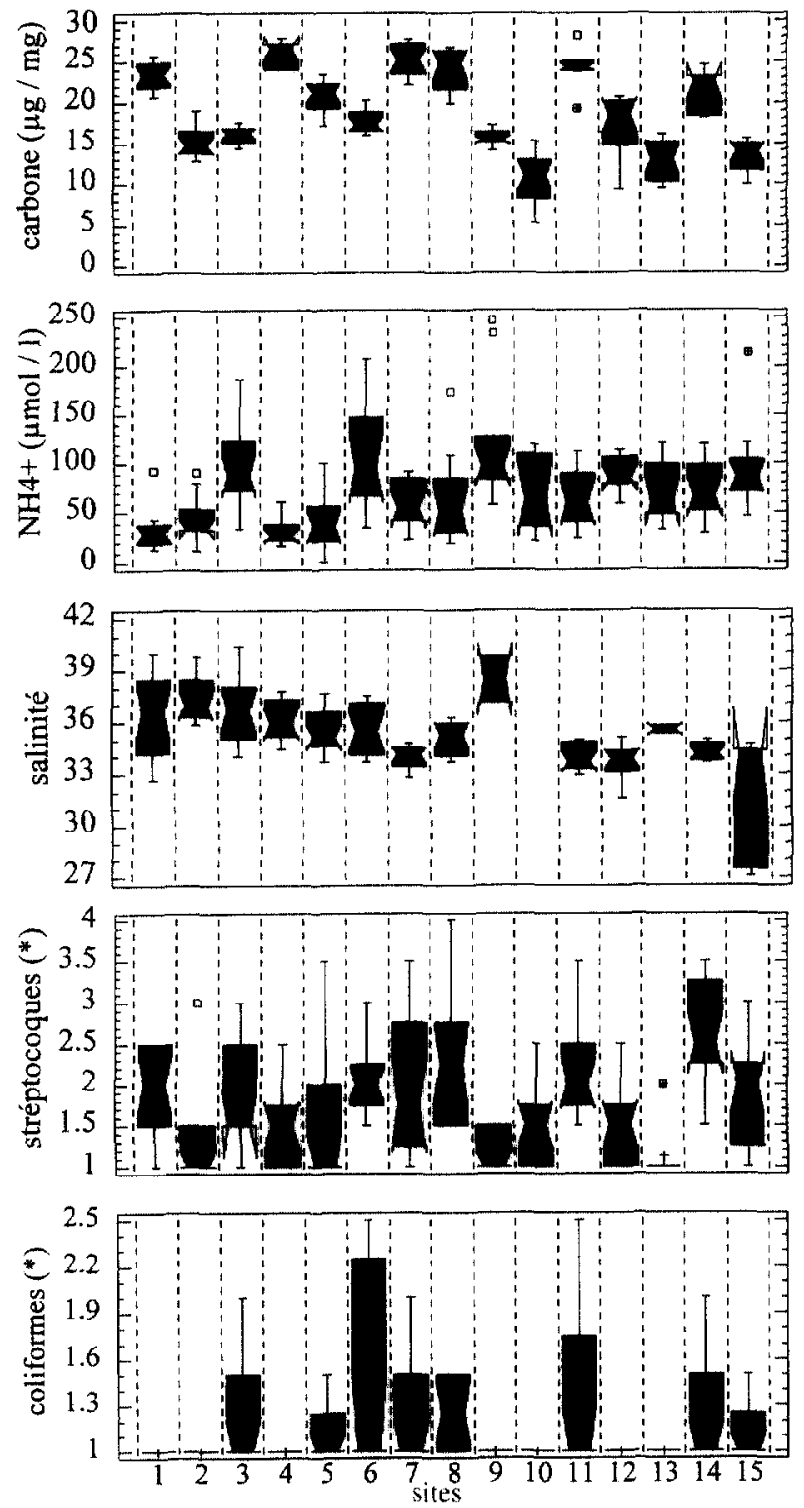

Figure 3. Paramètres environne-

mentaux des élevages sur le banc de Ronce. Teneur en carbone de la vase; teneur en azote ammoniacal et salinité de l'eau interstitielle ; streptocoques* et coliformes fécaux ${ }^{\text {*t }}$, de la vase. ", Échelle relative de contamination : 1 , inférieur au seuil de détection ; 2 , peu contaminé : 3 , légèrement contaminé ; 4 , contaminé ; 5 , fortement contaminé.

Figure 3. Environmental parameters on rearing areas on the RonceLes-Bains oyster bank. Organic carbon sediment concentration; ammoniac content and salinity of the sediment free water; streptococcus* and fecal coliforms* from the sediment. *, Relative scale of contamination: 1, below detection levels; 2 , barely contaminated; 3 , slightly contaminated; 4 , contaminated; 5 , very contaminated.

Deux matrices de corrélation sont établies avec les descripteurs biologiques et physiques pour les élevages à plat (tableau III) et sur tables (tableau IV). Elles montrent bien l'absence de relations entre la survie et les descripteurs du sédiment (carb, $\mathrm{NH}_{4}{ }^{+}$, sal) ou les coordonnées spatiales des sites $(x, y$ et $z$ ) tant pour les éleva- ges à plat que pour les élevages sur table $(p>0,05)$. Une seule corrélation significative $(p<0,05)$ apparaît entre la survie et la salinité de l'eau interstitielle pour les élevages sur tables (tableau IV). Un gradient négatif de salinité de l'eau interstitielle de la vase se développe selon un axe longitudinal en direction de la rivière Seudre. Une corrélation négative significalive $(p<0,05)$ apparaît entre la survie des huîtres et la salinité de cette eau interstitielle, traceur physique des effluents côtiers, vecteurs d'agents polluants potentiels. Aucune autre relation n'a pu être mise en évidence entre les caractéristiques sédimentaires du site (ou sa géographie), et la survie des cheptels.

\subsection{Saisonnalité de la mortalité et cycles biologiques}

La mortalité est saisonnière (figure 4). Durant les deux premiers mois du printemps, la mortalité cumulée n'atteint pas $3 \%$. La mortalité double durant le mois suivant pour atteindre $6 \%$ (le 19 juin). Elle double encore durant les deux premiers mois de l'été jusqu'à $12 \%$. Après la ponte (fin juillet, début août), le taux de mortalité se réduit considérablement et l'augmentation de la mortalité est de $1 \%$ seulement en 2 mois d'élevage (18 août-15 octobre). Le cycle de maturation (figure 5) suit l'évolution du cycle thermique (figure 4). La température passe de 10 à $25^{\circ} \mathrm{C}$ entre avril et août. L'augmentation des taux de mortalité est associée à des températures saisonnières supérieures à $20^{\circ} \mathrm{C}$ (figure 4) et aux valeurs de maturité sexuelle les plus fortes (7-8) (figure 5). La réduction très nette de la mortalité à la fin de l'été est associée à une température inférieure à $20^{\circ} \mathrm{C}$ (figure 4).

Au cours de cette étude, la ponte survient entre le 21 juillet et le 18 août. Les efforts de ponte moyens sont de $0,35 \pm 0,20 \mathrm{~g}$ pour les élevages à plat et de $0,80 \pm 0,29 \mathrm{~g}$ pour les élevages sur table. La différence obscrvée par analyse de variance est hautement significative $(p<0,001)$.

Pour les élevages sur tables, la maturité sexuelle augmente de mars à début juin, de 2 jusqu'à $7-8$, pour se stabiliser ensuite durant 1 mois, jusqu'à la ponte de juillet (figure 5). Pour les élevages à plat, l'augmentation du stade de maturité sexuelle [36] est encore significative $(6$ à 7,5$)$ au cours du mois de juin. L'évolution de la teneur des principaux constituants biochimiques de la chair de l'huître se distingue entre les élevages sur tables et à plat (figure 5). Ainsi, les huîtres élevées sur tables montrent une synthèse en sucres totaux encore active en début mai où les valeurs en glucides atteignent $15 \%$; celles des huîtres élevées à " plat » plafonnent à 3-7\% au cours du mois de mai. L'utilisation du glycogène de la chair commence début mai pour les huîtres en élcvage à plat, et 1 mois plus tard pour les huîtres en élevage sur tables. La teneur en lipides de la chair des huîtres, augmente au cours de la vitellogenèse de 8 à $11-14 \%$ jusqu'à la ponte de juillet, pour retomber à $10 \%$ en août et septembre (figure 5). 
Tableau III. Élevages « à plat . Matrice de corrélation entre les mesures biologiques et les facteurs environnementaux. Les corrélations sont : NS non significatives ou significatives au seuil de $5 \%(*)$, de $1 \%(* *)$, de $1 \%(* * *)$.

Table III. On-bottom oyster cultures. Correlation matrix between biological measurements and environmental parameters. Correlations are given at: NS, non significant; *, $\mathrm{P}<0.05 ; * *, \mathrm{P}<0.01 ; * *, \mathrm{P}<0.001$.

\begin{tabular}{|c|c|c|c|c|c|c|c|c|c|c|c|}
\hline & Survie & $P t$ & Ps & Ponte & gly(1) & $z$ & carb & $\mathrm{NH}_{4}^{+}$ & $x$ & $y$ & sal \\
\hline \multirow{3}{*}{$\begin{array}{l}\text { Survie } \\
P t\end{array}$} & 1 & & & & & & & & & & \\
\hline & -0.041 & & & & & & & & & & \\
\hline & NS & 1 & & & & & & & & & \\
\hline \multirow[t]{2}{*}{$P_{\mathrm{s}}$} & 0.053 & 0.925 & & & & & & & & & \\
\hline & NS & $* * *$ & $\mathrm{l}$ & & & & & & & & \\
\hline \multirow[t]{2}{*}{ Ponte } & 0.490 & 0.730 & 0.805 & & & & & & & & \\
\hline & NS & $*$ & $* *$ & 1 & & & & & & & \\
\hline \multirow[t]{2}{*}{ gly(1) } & 0.066 & 0.721 & 0.624 & 0.559 & & & & & & & \\
\hline & NS & $*$ & NS & NS & 1 & & & & & & \\
\hline \multirow[t]{2}{*}{$z$} & 0.224 & -0.794 & -0.771 & -0.493 & -0.509 & & & & & & \\
\hline & NS & $* *$ & $* *$ & NS & NS & 1 & & & & & \\
\hline \multirow[t]{2}{*}{ carb } & -0.249 & -0.451 & -0.322 & -0.379 & -0.532 & 0.209 & & & & & \\
\hline & NS & NS & NS & NS & NS & NS & 1 & & & & \\
\hline \multirow[t]{2}{*}{$\mathrm{NH}_{4}^{+}$} & -0.40 & 0.647 & 0.647 & 0.377 & 0.519 & -0.618 & -0.474 & & & & \\
\hline & NS & NS & * & NS & NS & NS & NS & 1 & & & \\
\hline \multirow[t]{2}{*}{$x$} & -0.595 & 0.564 & 0.526 & 0.151 & 0.421 & -0.696 & -0.161 & 0.872 & & & \\
\hline & NS & NS & NS & NS & NS & $*$ & NS & $* * *$ & 1 & & \\
\hline \multirow[t]{2}{*}{$y$} & -0.241 & 0.751 & 0.819 & 0.534 & 0.545 & -0.748 & -0.337 & 0.903 & 0.831 & & \\
\hline & NS & $*$ & $* * ;$ & NS & NS & $*$ & NS & $* * *$ & $* * *$ & 1 & \\
\hline \multirow[t]{2}{*}{ sal } & 0.585 & -0.486 & -0.409 & -0.258 & -0.342 & 0.532 & 0.125 & -0.819 & -0.831 & -0.686 & \\
\hline & NS & NS & NS & NS & NS & NS & NS & $* *$ & $* *$ & $*$ & 1 \\
\hline
\end{tabular}

(1) Teneur en glycogène le 21 juillet avant le début de la ponte.

(1) Glycogen content on July 21, before initiation of spawing.

Tableau IV. Les élevages « sur tables ». Matrice de corrélation entre les mesures biologiques et les facteurs environnementaux. Les corrélations sont : NS non significatives ou significatives au seuil de $5 \%(*)$, de $1 \%(* *)$, de $1 \%(* * *)$.

Table IV. Off-bottom oyster cultures. Correlation matrix between biological measurements and environmental parameters. Correlations are given at: NS, non significant; *. $\mathrm{P}<0.05 ;{ }^{* *}, \mathrm{P}<0.01 ; * * *, \mathrm{P}<0.001$.

\begin{tabular}{|c|c|c|c|c|c|c|c|c|c|c|c|}
\hline & Survie & $P t$ & $P_{\mathrm{s}}$ & Ponte & gly(1) & $z$ & carb & $\mathrm{NH}_{4}^{+}$ & $x$ & $y$ & sal \\
\hline Survie & 1 & & & & & & & & & & \\
\hline$P t$ & $\begin{array}{c}0.404 \\
\text { NS }\end{array}$ & 1 & & & & & & & & & \\
\hline$P_{\mathrm{S}}$ & $\begin{array}{c}0.404 \\
\text { NS }\end{array}$ & $\begin{array}{c}0.863 \\
* * *\end{array}$ & 1 & & & & & & & & \\
\hline Ponte & $\begin{array}{c}0.151 \\
\text { NS }\end{array}$ & $\begin{array}{c}0.825 \\
* * *\end{array}$ & $\begin{array}{c}0.679 \\
* *\end{array}$ & 1 & & & & & & & \\
\hline gly(1) & $\begin{array}{l}0.116 \\
\text { NS }\end{array}$ & $\begin{array}{c}0.741 \\
* *\end{array}$ & $\begin{array}{c}0.825 \\
* * *\end{array}$ & $\begin{array}{c}0.781 \\
* * *\end{array}$ & 1 & & & & & & \\
\hline$z$ & $\begin{array}{c}-0.373 \\
\text { NS }\end{array}$ & $-\underset{* * *}{0.833}$ & -0.654 & $\begin{array}{c}-0.573 \\
*\end{array}$ & $\begin{array}{c}-0.556 \\
*\end{array}$ & 1 & & & & & \\
\hline carb & $\begin{array}{c}0.169 \\
\text { NS }\end{array}$ & $\begin{array}{c}-0.383 \\
\text { NS }\end{array}$ & $\begin{array}{c}-0.378 \\
\text { NS }\end{array}$ & $\begin{array}{c}-0.503 \\
\text { NS }\end{array}$ & $\begin{array}{c}-0.477 \\
\text { NS }\end{array}$ & $\begin{array}{c}0.446 \\
\text { NS }\end{array}$ & 1 & & & & \\
\hline $\mathrm{NH}_{4}^{+}$ & $\begin{array}{l}0.196 \\
\text { NS }\end{array}$ & $\begin{array}{c}0.691 \\
* *\end{array}$ & $\begin{array}{c}0.810 \\
* * *\end{array}$ & $\begin{array}{c}0.491 \\
\text { NS }\end{array}$ & $\begin{array}{c}0.683 \\
* *\end{array}$ & $\begin{array}{c}-0.519 \\
*\end{array}$ & $\begin{array}{c}-0.557 \\
*\end{array}$ & 1 & & & \\
\hline$x$ & $\begin{array}{l}0.469 \\
\text { NS }\end{array}$ & $\begin{array}{c}0.604 \\
*\end{array}$ & $\begin{array}{c}0.236 \\
\text { NS }\end{array}$ & $\begin{array}{c}0.403 \\
\text { NS }\end{array}$ & $\begin{array}{c}-0.029 \\
\text { NS }\end{array}$ & $\begin{array}{c}-0.645 \\
*\end{array}$ & $\begin{array}{c}0.091 \\
\text { NS }\end{array}$ & $\begin{array}{c}0.168 \\
\text { NS }\end{array}$ & 1 & & \\
\hline$y$ & $\begin{array}{c}0.481 \\
\text { NS }\end{array}$ & $\begin{array}{c}0.937 \\
* * * *\end{array}$ & $\begin{array}{c}0.781 \\
* * *\end{array}$ & $\begin{array}{c}0.793 \\
* * * *\end{array}$ & $\begin{array}{c}0.592 \\
*\end{array}$ & $\begin{array}{c}-0.774 \\
\star \star\end{array}$ & $\begin{array}{c}-0.335 \\
\text { NS }\end{array}$ & $\begin{array}{c}0.637 \\
*\end{array}$ & $\begin{array}{c}0.745 \\
* *\end{array}$ & 1 & \\
\hline sal & $\begin{array}{c}-0.621 \\
*\end{array}$ & $\begin{array}{c}-0.407 \\
\text { NS }\end{array}$ & $\begin{array}{c}-0.128 \\
\text { NS }\end{array}$ & $\begin{array}{c}-0.202 \\
\text { NS }\end{array}$ & $\begin{array}{c}0.190 \\
\text { NS }\end{array}$ & $\begin{array}{c}0.333 \\
\text { NS }\end{array}$ & $\begin{array}{c}-0.207 \\
\text { NS }\end{array}$ & $\begin{array}{c}0.040 \\
\mathrm{NS}\end{array}$ & $\begin{array}{c}-0.750 \\
* *\end{array}$ & $\begin{array}{c}-0.450 \\
\text { NS }\end{array}$ & 1 \\
\hline
\end{tabular}

(1) Teneur en glycogène le 21 juillet avant le début de la ponte

(I) Glycogen content on July 21, before initiation of spawing. 
Figure 4. Mortalité cumulée et température moyenne de l'air.

Figure 4. Cumulated mortality rate and mean air temperature.

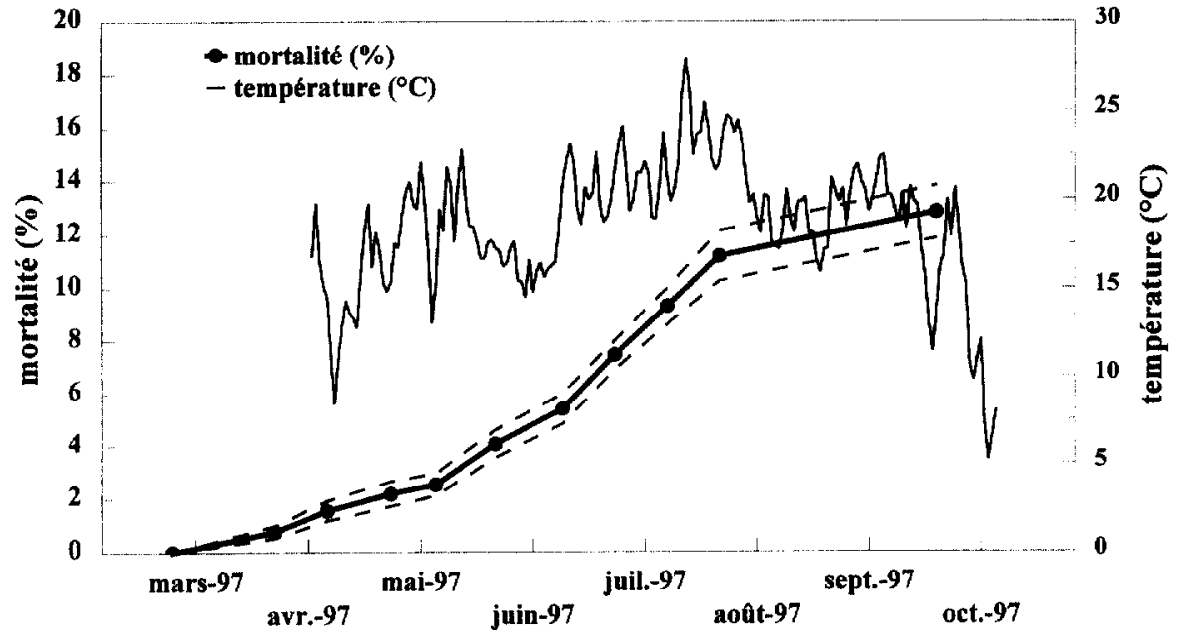

\subsection{Croissance et modèles de production}

Le 15 octobre, après $204 \mathrm{j}$ d'élevage, le poids total des huîtres est compris entre 45-67g pour les élevages à plat, et entre $50-68 \mathrm{~g}$ pour les élevages sur tables. Le poids de coquille est de $27-37$ g pour le plat, et de 31$40 \mathrm{~g}$ pour les élevages sur tables. Le poids sec moyen des huîtres en élevages sur table est de 1,61 $\pm 0,02 \mathrm{~g}$. Il est significativement supérieur $(p<0,01)$ au poids sec moyen de $1,46 \pm 0,03 \mathrm{~g}$ des élevages à plat. L'effet du type d'élevage n'est pas significatif $(p>0,05)$ sur la croissance en poids total (tableau $V$ ). Il est significatif $(p<0,001)$ pour le poids de coquille et le poids sec. L'effet du facteur " site " est toujours très significatif $(p<0,001)$ pour les différentes mesures de biométrie (tableau V). Pour les deux types d'élevage (plat et tables), les sites 13 et 15 sur la partie nord-est du banc de Ronce (figure l) sont les sites les plus performants (figure 6). Les interactions entre les facteurs « sites" et "type d'élevage " sont également significatives (tableau V) grâce aux sites 7 et 14 au sud-est du banc sur lesquels les performances des élevages à plat sont plus faibles.

Des corrélations significatives $(p<0,05)$ apparaissent entre les variables de croissance : $P \mathrm{t}, P \mathrm{~s}$ et l'altitude $(z)$ et la longitude $(y)$ des sites pour les deux types d'ćlevage (tableau III, IV). Des corrélations positives $(p<0,01)$ sont établies entre la concentration en azote ammoniacal de l'eau interstitielle et le poids total et celui de chair sèche des huîtres pour les élevages sur tables.

La croissance des élevages à plat et sur tables sont des fonctions de la latitude $(x)$, longitude $(y)$ et altitude (z) des sites (tableau $V I$ ). Les modèles présentent des coefficients de corrélation de 0,82-0,94 pour les élevages sur tables supéricurs à ceux obtenus avec les élevages à plat $(0,67-0,72)$. La production de chair est fonction de la longitude $(y)$ et de la latitude $(x)$ quel que soit le type d'élevage. La profondeur n'intervient pas comme variable explicative de ces modèles. La production de coquille et le gain de poids total sont

Aquat Living Resour. 12 (2) (1999) fonction de la longitude $(y)$ et altitude $(z)$ des parcs dans le cas des élevages sur table. Pour les élevages à plat, ces deux productions ne sont dépendantes que de la profondeur. Ces résultats montrent le meilleur ajustement de la croissance des huîtres élevées sur tables avec la profondeur et la situation géographique des sites. Les lignes d' « isoproduction » (isoplèthes de production) de chair (soma + gamètes), sont situées dans l'axe longitudinal du banc de Ronce (figure 7). Le gradient de production se situe ainsi dans un axe perpendiculaire au banc au nord-nord-ouest, en direction de la pointe sud de l'île d'Oléron et du pertuis de Maumusson. Cette orientation est la même, qu'il s'agisse des élevages sur tables ou des élevages à plat, mais dans une gamme de production inférieure pour les élevages à plat (3-15 $\left.\mathrm{mg} \cdot \mathrm{j}^{-1}\right)$ par rapport aux élevages sur table $\left(6-20 \mathrm{mg} \cdot \mathrm{j}^{-1}\right)$. Les modèles de production de coquille (figure 7) sont voisins des modèles de production de poids total, dans le cas des élevages sur tables et à plat. Le gradient de production positif est dans un axe orienté au nord et lié à la profondeur du site. La production en poids total est comprise entre 52-190 et 46$184 \mathrm{mg} \cdot \mathrm{j}^{-1}$ respectivement pour les élevages à plat et sur table. Pour le gain de coquille, la production est de $32-110$ et $35-113 \mathrm{mg} \cdot j^{-1}$ respectivement pour les élevages à plat et sur table (tableau VII). Si les écarts de production entre les élevages à plat et sur tables sont souvent peu importants dans la partie sud-ouest du banc, les différences deviennent de plus en plus marquées en se déplaçant vers le nord - est du banc (figure 7).

Les rendements biologiques moyens sont respectivement de 13 et $44 \%$ pour les élevages à plat et sur table sur le banc ostréicole de Ronce. Pour les élevages sur table, le rendement biologique le plus faible est de $2,2 \%$ sur le site 2 à l'ouest du banc (figure 8). Ces rendements atteignent $85 \%$ sur la partie nord-est du banc (sites 13 et 15). Sur le plat, les rendements peuvent devenir négatifs ( -2 à $-9 \%)$ dans la partie sud du banc (sites 1, 7 et 14) (figure 8). 

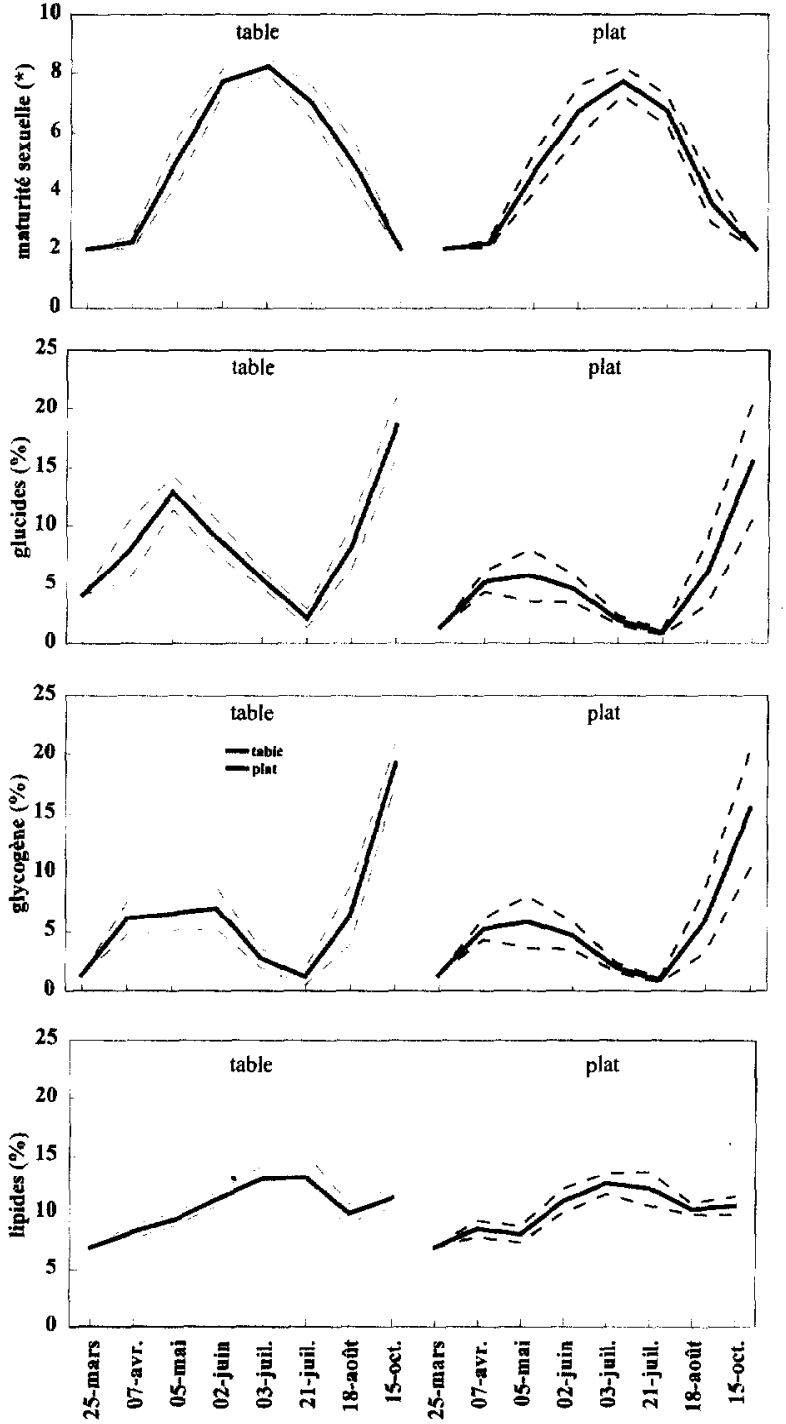

Figure 5. Maturité sexuelle (selon une échelle relative de maturité sexuelle de 1 à 9 [36]),composition en glucides totaux (\%), glycogène $(\%)$ et lipides (\%) de la chair sèche de l'huître $C$. gigas en élevage à plat et sur tables ostréicoles du banc de Ronce.

Figure 5. Sexual maturation (based upon a 9-level maturation scale (36]), total carbohydrate content (\%), glycogen content (\%) and lipid content (\%) of the dry meat of the oyster $\mathrm{C}$. gigas reared using on-and off-bottom types of culture on the Ronce-les-Bains oyster bank.

\section{DISCUSSION}

La différence de croissance en poids sec et poids de coquille au cours des élevages est de +7 et $+11 \%$ à l'avantage des élevages sur table. La différence d'altitude entre plat et table, d'environ $50 \mathrm{~cm}$, représente une différence d'immersion de 4 à $10 \%$ au détriment des élevages sur table. Les cheptels sur table ont donc un temps d'accès à la ressource alimentaire inférieur aux huîtres à plat. En revanche, la surélévation des huîtres sur les tables leur permet un meilleur accès au
Tableau V. Analyse de variance des descripteurs de la croissance des huîtres : poids total $(P \mathrm{t})$, poids de coquille $(P \mathrm{c})$, poids sec de chair $(P \mathrm{~s})$, sur le banc de Ronce après 7 mois d'élevage. Effet du type d'élevage (*, plat et table) et de la zone géographique (site) sur ces descripteurs.

Table V. Analysis of variance of oyster growth: total weight (Pt), shell weight ( $\mathrm{Pc}$ ), dry flesh weight (Ps) on the Ronce oyster bank after 7 months rearing. Effect of culture ( ${ }^{*}$ ) (on- and off-bottom cultures) and site on the previous descriptive elements. Ddl, Degree of freedom.

\begin{tabular}{|c|c|c|c|c|}
\hline & $\begin{array}{c}\text { Carré } \\
\text { des écarts }\end{array}$ & ddl & $\begin{array}{c}\mathbf{F} \\
\text { de Fisher }\end{array}$ & $\begin{array}{c}\text { Probabilité } \\
(p)\end{array}$ \\
\hline \multicolumn{5}{|l|}{$P t(\mathrm{~g})$} \\
\hline Élevage $\left({ }^{*}\right)(\mathrm{E})$ & 403 & 1 & 3,1 & $p>0,05$ \\
\hline Site (S) & 49146 & 9 & 42,5 & $p<0,001$ \\
\hline Interaction $(\mathrm{E} \times \mathrm{S})$ & 4350 & 9 & 3,8 & $p<0,001$ \\
\hline Résidus & 72954 & 568 & & \\
\hline Total & 126557 & 587 & & \\
\hline \multicolumn{5}{|l|}{$P_{\mathrm{c}}(\mathrm{g})$} \\
\hline Élevage $(*)(E)$ & 721 & 1 & 14,3 & $p<0,001$ \\
\hline Site (S) & 14981 & 9 & 33,0 & $p<0,001$ \\
\hline Interaction $(E \times S)$ & 912 & 9 & 2,0 & $p<0,05$ \\
\hline Résidus & 28691 & 568 & & \\
\hline Total & 45246 & 578 & & \\
\hline \multicolumn{5}{|l|}{$P s(g)$} \\
\hline Élevage $\left(^{*}\right)(\mathrm{E})$ & 3,5 & 1 & 19,1 & $p<0,001$ \\
\hline Site (S) & 115 & 9 & 68,9 & $p<0,001$ \\
\hline Interaction $(\mathrm{E} \times \mathrm{S})$ & 4,9 & 9 & 2,9 & $p<0,01$ \\
\hline Résidus & 105 & 567 & & \\
\hline Total & 228 & 586 & & \\
\hline
\end{tabular}

volume d'eau environnant. Par ailleurs, la vitesse d'écoulement de la masse d'eau est réduite au niveau du sédiment par des forces de frottement. La turbidité peut devenir un facteur limitant de l'activité de filtration de l'huître, au-delà de $200 \mathrm{mg} \cdot \mathrm{L}^{-1}$ [32]. Ces deux éléments vont dans le sens d'une diminution de l'accès à la ressource des huîtres à plat par rapport aux huîtres sur tables, contrairement à ce que laissait supposer la différence d'altitude entre les deux types d'élevage.

Dans le cadre de cette étude, des mortalités de 8$19 \%$ sur tables en 7 mois d'élevage ne sont pas exceptionnelles comparées aux mortalités estivales rencontrées dans le bassin de Marennes-Oléron depuis 1985, entre 2 et $18 \%$ [21]. Les mortalités des élevages à plat, de 23-33\% sont significativement plus élevées. Vers la mi-juillet, la mortalité cumulée des élevages à plat est comparable en 1997 aux résultats obtenus sur le même site de Ronce en 1996 [21]. Les médianes de taux de mortalité sont à $19 \%$ à cette date et pour les deux années consécutives. En 1997, en l'absence d'ćpisodes de mortalité aiguë, la mortalité sur table autour de $10 \%$ apparaît comme " normale ». La différence significative rencontrée avec les élevages à plat, « désigne » une nouvelle fois l'interface eau-sédiment comme responsable de cette situation.

Parmi les facteurs étudiés, les caractéristiques du site (nature du sédiment, richesse en matière organique, streptocoques et coliformes fécaux) ne permettent pas d'expliquer les mortalités rencontrées sur les élevages à plat. Le suivi bactériologique effectué sur 

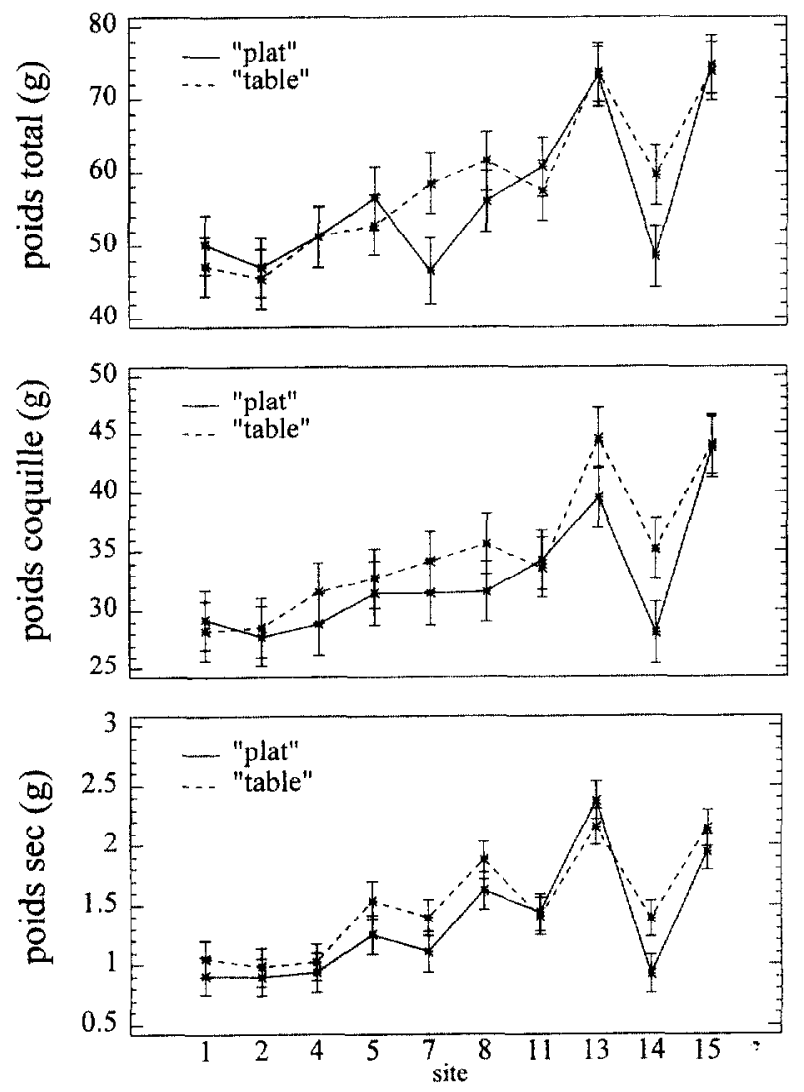

Figure 6. Croissance de l'huître $C$. gigas sur le banc de Ronce, en élevage à plat et sur tables ostréicoles : poids total (g) : poids de coquille (g) ; poids sec $(\mathrm{g})$.

Figure 6. Growth of the on-and off-bottom cultures of oysters on the Ronce-Les-Bains oyster bank: total weight $(g)$, shell weight $(g)$ and dry meat weight.

Tableau VI. Modèles de croissance de Crassostrea gigas sur le site ostréicole de Ronce au cours du printemps-été $1997(x, y$ et $z$ représentent respectivement la latitude, la longitude et l'altitude).

Table VI.Growth models of Crassostrea gigas on Ronce-Les-Bains oyster bank during spring-summer 97 ( $\mathrm{x}, \mathrm{y}$ and $\mathrm{z}$, respectively, represent the latitude. longitude and altitude)

\begin{tabular}{|c|c|c|}
\hline Élevage & Modèles & $R^{2}$ \\
\hline \multicolumn{3}{|c|}{ Production de chair (soma et gamètes) $\left(\mathrm{mg} \cdot \mathrm{j}^{-1}\right.$ ) } \\
\hline table & $P r_{\mathrm{s}}=5,530-0,00411(x)+0,0139(y)$ & 0,82 \\
\hline plat & $P r_{s}=3,204-0,00603(x)+0,0146(y)$ & 0,72 \\
\hline \multicolumn{3}{|c|}{ Production en poids total $\left(\mathrm{mg} \cdot \mathrm{j}^{-1}\right)$} \\
\hline table & $p r_{1}=142,18+0,0705(y)-29,16(z)$ & 0,94 \\
\hline plat & $P r_{1}=-78,85+458,1 /(z)$ & 0,72 \\
\hline \multicolumn{3}{|c|}{ Production en poids de coquille $\left(\mathrm{mg} \cdot \mathrm{j}^{-1}\right.$ ) } \\
\hline table & $P r_{\mathrm{c}}=75,18+0,044(y)-13,79(z)$ & 0,92 \\
\hline plat & $\operatorname{Pr}_{\mathrm{c}}=-36,25+230,7 /(z)$ & 0,67 \\
\hline
\end{tabular}

les bancs de Ronce n'a pas mis en évidence de contaminations aiguës au niveau du sédiment. Les cheptels d'huîtres en place sur les sites du banc les plus côtiers, riches en matière organique, ne présentent pas de mortalité supérieure aux autres sites.
Des différences thermiques apparaissent entre les élevages à plat et sur table lors des pics de température en périodes d'assec [21]. En périodes chaudes, la température peut être de $10^{\circ} \mathrm{C}$ supérieure au niveau des élevages à plat. La durée d'exondation des cheptels comprise entre 20 et $55 \%$ ainsi que la nature du sédiment régissent les conditions d'exposition thermique des cheptels. Dans le cadre de cette étude, aucune relation directe n'a pu être démontrée entre les durées d'émersion des cheptels et leur taux de mortalité. Ainsi, le site 2, à l'ouest du bassin, connaît le taux de survie «à plat " le plus élevé ( $77 \%$ ) malgré une faible productivité. La température ne peut donc être évoquée comme seul «agent causal » des épisodes de mortalité d'huîtres. Des effets « seuils » ou « synergiques » sont à rechercher à travers des analyses non linéaires de son influence sur la mortalité.

Bien que les sites expérimentaux se distinguent par leurs caractéristiques physiques, ces facteurs ne sont pas suffisants pour expliquer les différences de mortalités observées entre des sites distants de quelques centaines de mètres sur un parc ostréicole de 250 ha. L'une des originalités de cette étude est de montrer la grande variabilité dans les taux de survie (mais également dans la croissance) des huîtres sur une aussi petite surface quand d'autres études comparent des cheptels répartis sur des centaines de kilomètres de côtes [8].

L'activité de gamétogenèse chez l'huître est associée à une accumulation et une utilisation de réserves. La teneur en sucre de la chair des huitres varie inversement avec la gamétogenèse $[1,24]$. Les zones géographiques où surviennent de fortes mortalités d'huîtres sont souvent des baies soumises à l'eutrophisation [10, 29]. Le stress physiologique issu d'un état de matura. tion avancée et d'une température élevée (supérieure à $20^{\circ} \mathrm{C}$ ) est souvent évoqué pour expliquer les mortalités estivales $[8,11,18,29,31,39]$. Dans le bassin de Marennes-Oléron, les huîtres élevées sur tables sont en maturation sexuelle avancee durant tout le mois de juin. Durant cette même période, les réserves de glycogène chutent pour atteindre de faibles valeurs $(1-2 \%)$ au cours de la seconde quinzaine de juillet, juste après la ponte. Même si aucune crise de mortalité n'apparaît, c'est au cours de cette période, avec une temperature supérieure à $20^{\circ} \mathrm{C}$, que les taux de mortalité enregistrés ont été les plus forts. De nombreux auteurs font référence à ce seuil thermique «à risque " de $20^{\circ} \mathrm{C}$ pour Crassostrea gigas [11, 19]. Des stress thermiques de $28^{\circ} \mathrm{C}$, identiques à ceux rencontrés dans le milieu naturel pour les élevages à plat, entraînent une augmentation significative de la dépense énergétique associée à la respiration. En 1996, une crise de mortalité aiguë est observée à la mi-juin, à un stade avancé de maturité sexuelle des huîtres. À cette période, la température de l'air passe en quelques jours de 24 à $33^{\circ} \mathrm{C}$ [21]. En 1997, aucune « crise » de mortalité n'apparait. La température reste comprise entre 16 et $22^{\circ} \mathrm{C}$ du 10 juin au 5 juillet durant la période physiologique «à risques». Ainsi se trouve confirmée in situ la fragilité physiologique de l'huître creuse, observée 


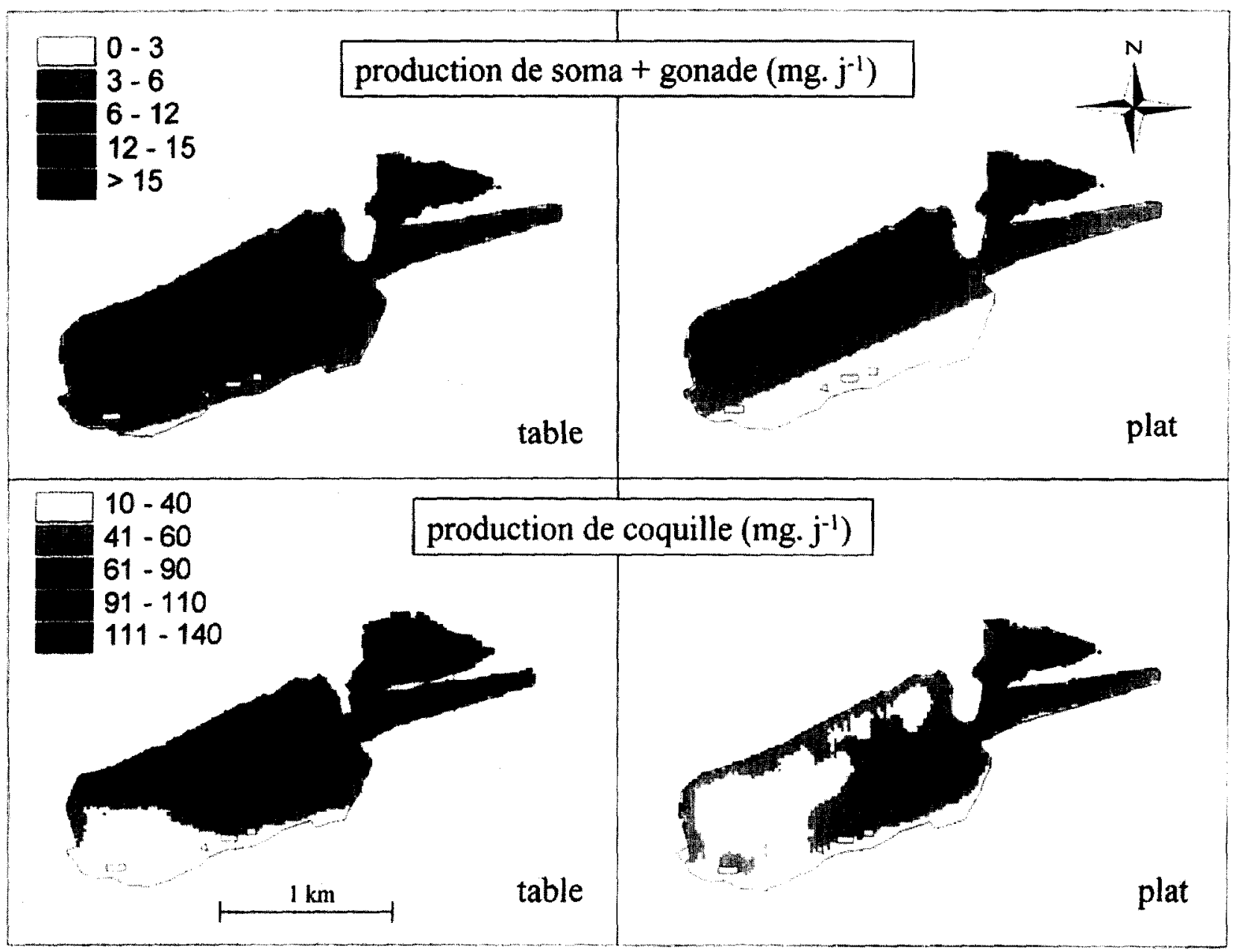

Figure 7. Modèles spatiaux de production de chair sèche et de poids de coquille $\left(\mathrm{mg} \cdot \mathrm{j}^{-1}\right)$ sur table et à plat.

Figure 7. Spatial production models of dry meat weight and shell weight (mg.d $d^{-1}$ ) for off-and on-bottom cultures.

en laboratoire à un stade de maturation avancée [36]. Toutefois, la faible mortalité d'huîtres obtenue dans cette étude laisse entendre que d'autres facteurs doivent être « suspectés » pour expliquer les mortalités estivales de $C$. gigas. Entre les élevages à plat et les élevages sur table, la cinétique d'utilisation des réserves en glycogène diffère significativement. Leur utilisation commence début mai, pour les élevages à plat, et seulement 1 mois plus tard pour les élevages sur table. Cette observation est le reflet d'une situation physiologique pouvant, à terme, entraîner des différences de mortalité entre les deux types d'élevage. La mortalité saisonnière augmente de façon significative à partir de la première quinzaine de juin pour les élevages sur table, et dès le mois de mai pour les élevages à plat, au moment où l'utilisation des réserves de glycogène devient importante [4]. La différence entre les élevages sur tables et à plat apparaît également bien dans l'évolution de la teneur en glucides totaux de la chair des huîtres. Les huîtres élevées sur table doublent pratiquement les réserves de glucides au cours du mois d'avril, en début de vitellogenèse $(+95 \%)$, quand les huîtres à plat n'augmentent leurs réserves en glucides que de $20 \%$ durant la même période.

Les modèles de production de chair d'huîtres (soma et gamètes), présentent un gradient positif orienté vers la pointe sud de l'île d'Oléron et en direction du pertuis de Maumusson. La croissance organique semble sous la dépendance d'un flux alimentaire en provenance du nord du bassin et (ou) du pertuis de Maumusson. Ce flux serait progressivement utilisé sur le banc ostréicole, par les cheptels en élevage. Ce schéma renforce l'hypothèse de la limitation de la ressource trophique dans le bassin de Marennes-Oléron [16] et plus particulièrement dans le sud du bassin pour lequel la charge en élevage est 2,5 fois supérieure à la partie nord [37]. En revanche, les modèles de croissance en poids de coquille et poids total, pour les deux types d'élevage, prennent en compte la profondeur des sites. La production décroît quand le temps d'émersion augmente [12]. 
Tableau VII. Valeurs de production sur plat et sur table en poids total $\left(P r_{\mathrm{t}}\right)$, de coquille $\left(P r_{\mathrm{c}}\right)$ et de matière organique $\left(P r_{\mathrm{s}}\right)\left(\mathrm{mg} \cdot \mathrm{j}^{-1}\right)$.

Table VII. Production values for on- and off-bottom oyster cultures concerning total weight $\left(\operatorname{Pr}_{t}\right)$, shell weight $\left(\operatorname{Pr}_{c}\right)$ and dry meat weight $\left(\operatorname{Pr}_{s}\right)\left(m g \cdot d^{-3}\right)$.

\begin{tabular}{|c|c|c|c|c|c|c|}
\hline \multirow[t]{2}{*}{ Sites } & \multicolumn{2}{|c|}{$P r_{i}$} & \multicolumn{2}{|c|}{$P r_{\mathrm{c}}$} & \multicolumn{2}{|c|}{$\operatorname{Pr}_{\mathrm{s}}$} \\
\hline & plat & table & plat & table & plat & table \\
\hline 1 & $69,10 \pm 3,23$ & $54,90 \pm 1,50$ & $39,08 \pm 1,95$ & $34,52 \pm 0,90$ & $3,33 \pm 0,29$ & $6,76 \pm 0,39$ \\
\hline 2 & $53,92 \pm 2,69$ & $46,57 \pm 1,40$ & $32,30 \pm 1,69$ & $35,78 \pm 1,11$ & $4,72 \pm 0,43$ & $8,87 \pm 0,27$ \\
\hline 3 & & $123,04 \pm 4,01$ & & $73,51 \pm 2,44$ & & $15,10 \pm 0,68$ \\
\hline 4 & $74,51 \pm 3,51$ & $74,51 \pm 1,49$ & $37,18 \pm 1,94$ & $50,23 \pm 0,96$ & $4,25 \pm 0,38$ & $5,94 \pm 0,29$ \\
\hline 5 & $100.55 \pm 4.41$ & $82,35 \pm 2,19$ & $49,91 \pm 2,45$ & $55,91 \pm 1,38$ & $8,59 \pm 0,58$ & $9,15 \pm 0,36$ \\
\hline 6 & & $136,76 \pm 3,06$ & & $75,45 \pm 1,91$ & & $13,98 \pm 0,72$ \\
\hline 7 & $52,08 \pm 2,91$ & $109,80 \pm 3,93$ & $50,15 \pm 2,54$ & $62,88 \pm 2,21$ & $6,41 \pm 0,52$ & $11,32 \pm 0,57$ \\
\hline 8 & $98,04 \pm 4.24$ & $125,00 \pm 3,48$ & $50,53 \pm 2.34$ & $70.11 \pm 2.01$ & $9,82 \pm 0,51$ & $15,03 \pm 0,64$ \\
\hline 9 & & $134,80 \pm 4,05$ & & $83,85 \pm 2,96$ & & $15,09 \pm 0,67$ \\
\hline 10 & & $135,29 \pm 3,59$ & & $84,48 \pm 2,80$ & & $13,46 \pm 0,93$ \\
\hline 11 & $121,61 \pm 4,72$ & $104,90 \pm 3,70$ & $63,59 \pm 2,68$ & $60,39 \pm 2,20$ & $7,37 \pm 0,41$ & $10,02 \pm 0,43$ \\
\hline 12 & & & $40,74 \pm 2,05$ & $96,10 \pm 3,40$ & & \\
\hline 13 & $181,95 \pm 5,80$ & $184,31 \pm 5,98$ & $88,95 \pm 3,29$ & $113,43 \pm 3,61$ & $14,74 \pm 0,50$ & $20,48 \pm 1,04$ \\
\hline 14 & $61,39 \pm 3,02$ & $115,20 \pm 2,65$ & $33,52 \pm 1,74$ & $67,93 \pm 1,65$ & $2,23 \pm 0,20$ & $9,40 \pm 0,41$ \\
\hline 15 & $189,73 \pm 5,98$ & $184,80 \pm 5,62$ & $109,66 \pm 3,73$ & $110,82 \pm 3,62$ & $12,42 \pm 0,52$ & $18,64 \pm 1,04$ \\
\hline
\end{tabular}

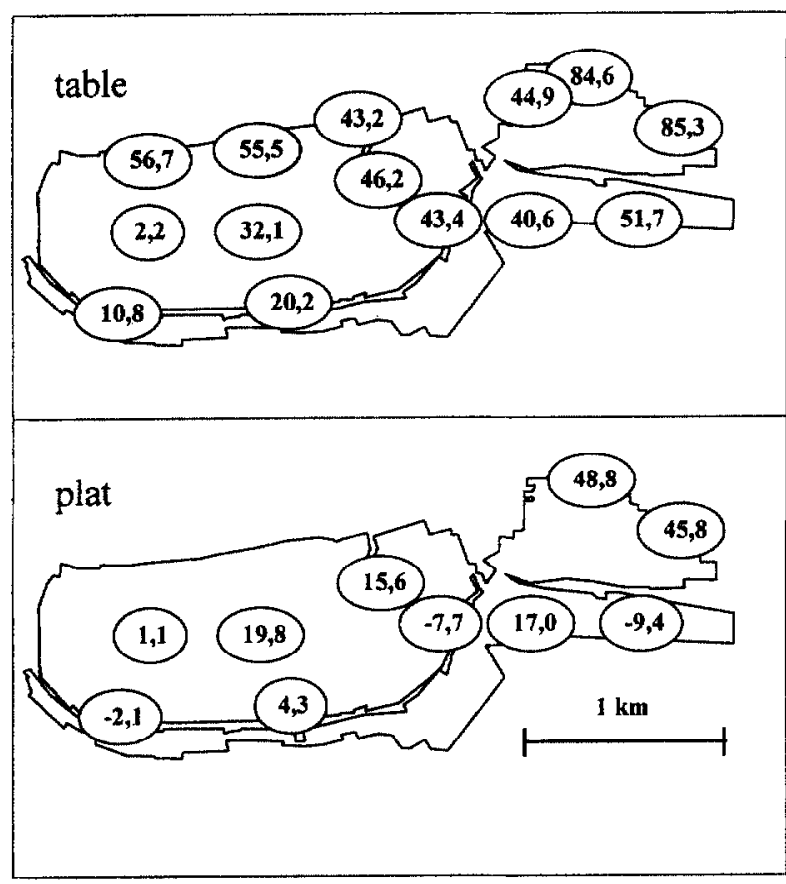

Figure 8. Rendements biologiques $(\%)$ après 7 mojs d'élevage de l'huître $C$.gigas sur table et à plat.

Figure 8. Yields (\%) after 7 months in on-and off-bottom rearing conditions.

La surface du bassin de Marennes-Oléron entre les deux pertuis est d'environ 18000 ha. La surface concédée à l'ostréiculture représente $15 \%$ de cette surface. La capacité trophique du bassin varie selon les espèces en culture [13] et doit prendre en compte toute la population de bivalves dont la capacité de filtration de la colonne d'eau est significative [34]. Les études se succèdent sur ce site $[2-4,29]$. Aujourd'hui, la charge en huîtres est d'environ $145 \mathrm{~kg} \cdot 10^{-3} \mathrm{~m}^{-3}$ dans le nord, et de $360 \mathrm{~kg} \cdot 10^{-3} \mathrm{~m}^{-3}$ dans le sud du bassin [37]. Une biomasse actuelle d'huitres creuses de plus de 100000 tonnes exploite largement la ressource trophique de l'écosystème [16]. Les huîtres filtrent en $3 \mathrm{j}$ l'ensemble du volume du bassin, quand le temps de résidence est de 6 à $9 \mathrm{j}$ [20]. Des observations sur 1'exhaussement des bancs ostréicoles et des pertuis laissent à penser que le temps de résidence dans le sud du bassin de Marennes-Oléron augmente [37]. L'étude des tendances pluriannuelles depuis 1978 montre que la température de l'eau de mer s'est élevée de $1,5^{\circ} \mathrm{C}$ en 18 ans, ce qui n'est pas sans conséquence sur la physiologie de l'huître [37]. L'ensemble de ces observations montre que la capacité trophique du bassin se réduit. Cette évolution doit être prise en compte dans la gestion des élevages.

Au-delà des contraintes qu'elle génère, la nouvelle situation hydrodynamique du bassin peut engendrer des situations dystrophiques (hypoxies, élévations de la teneur en azote ammoniacal) responsables de crises de mortalité de coquillages comme en connaît le bassin depuis quelques années.

\section{CONCLUSION}

La mortalité des huîtres au cours de l'année 1997 n'est pas supérieure à celle des trois dernières années sur le secteur géographique du banc de Ronce. L'importance de la mortalité associée au mode de culture à plat est confirmée. L'effort de recherche effectué sur l'environnement des élevages ne permet pas d'expliquer la forte mortalité obtenue pour les élevages à plat. Aucune relation de cause à effet n'a pu être observée avec la nature du sédiment, son niveau d'infestation bactérienne, le temps d'exondation des cheptels sur les sites et la température. La variabilité de réponse entre les sites est importante sur une surface géographique aussi restreinte. 
La saisonnalité de la mortalité de $C$. gigas est confirmée in situ en relation avec les températures estivales élevées, la maturation sexuelle et le catabolisme du glycogène, pour les élevages sur table. Ce résultat confirme, in situ, la fragilité physiologique des cheptels durant cette période printanière et en période de préponte. Les risques encourus deviennent de plus en plus forts et des mortalités « chroniques » de 20 à $25 \%$ des cheptels au cours de la saison printanière et estivale affectent la productivité de la zone.
Les modèles de production de chair et de coquille sont géographiquement orientés pour les deux élevages, à « plat » et « surélevés ». Leur présentation au moyen d'un SIG (système d'informations géographiques) montre les limites de la capacité trophique dans le sud du bassin de Marennes-Oléron et, en particulier, dans cette zone comprise entre le pertuis de Maumusson et la rivière Seudre. Les sites les moins performants se trouvent dans le sud-ouest du banc de Ronce.

\section{Remerciements}

À la Section régionale conchylicole (SRC) du bassin de Marennes-Oléron et le Comité du banc de Ronce pour leur soutien dans la réalisation de ces opérations de recherche.

\section{RÉFÉRENCES}

[1] Allen S.K., Downing S.L., Performance of triploid Pacific oystcrs, Crassostrea gigas (Thunbcrg). I. Survival, growth, glycogen content and sexual maturation in yearlings, J. Exp. Mar. Biol. Ecol. 102 (1986) 197208

[2] Bacher C., Capacité trophique du bassin de MarennesOléron : couplage d'un modèle de transport particulaire et d'un modèle de croissance de l'huître Crassostrea gigas, Aquat. Living. Resour. 2 (1989) 199-214.

[3] Bacher C., An energy model of the growth oyster (Crassostrea gigas) in the Bay of Marennes-Oléron, Can. J. Fish. Aquat. Sci. 48 (1991) 391-404.

[4] Bayne B.L., The physiology of suspension feeding by bevalve molluscs: an introduction to the Plymouyh 'TROPHEE' workshop, J. Exp. Mar. Biol. Ecol. 219 (1998) 1-21.

[5] Beattie J.H., Chew K.K., Hershberger W.K., Differential survival of selected strains of Pacific Oysters (Crassostrea gigas) during summer mortality, Proc. Natl. Shellfish. Assoc. 70 (1980) 184-189.

[6] Bodoy A., Garnier J., Razet D., Geairon P., Mass mortalities of oysters (Crassostrea gigas) during spring 1988 in the bay of Marennes-Oléron, related to environmental conditions, Cons. Int. Exp. Mer, C.M. 90/K 11, 1988, pp. 1-23.

[7] Bougrier S., Geairon P., Deslous-Paoli J.M., Bacher C., Jonquières G., Allometric relationships and effects of temperature on clearance and oxygen consumption rates of Crassostrea gigas (Thunberg), Aquaculture 134 (1995) 143-154.

[8] Brown J.R., Hartwick E.B., Influences of temperature, salinity and available food upon suspended culture of the Pacific oyster, Crassostrea gigus. II. Condition index and survival, Aquaculture 70 (1988) 253-267.

[9] Farley C.G., Mass mortalities and infectious lethal diseases in bivalve molluscs and association with geographic transfers of populations, in : Rosenfield A., Mann R. (Eds.), Dispersal of Living Organisms into
Aquatic Ecosystems, Maryland Sea Grant Publishers, College Park, Maryland, 1992, pp. 139-155.

[10] Friedman C.S., Beattie J.H., Elston R.A., Hedrick R.P., Investigation of the relationship between the presence of a Gram-positive bacterial infection and summer mortality of the Pacific oyster, Crassostrea gigas (Thunberg), Aquaculture 94 (1991) 1-15.

[11] Glude J.B., A summary report of the Pacific Coast oyster mortality investigations 1965-1972, Proc. 3rd US-Japan Meeting Aquaculture in Tokyo, Japan, October 15-16 1974, 1975, $28 \mathrm{p}$.

[12] Goulletquer P., Lombas I., Prou J., Influence du temps d'immersion sur l'activité reproductrice et sur la croissance de la palourde japonaise Ruditapes philippinarum et l'huître japonaise Crassostrea gigas, Haliotis 16 (1987) 453-462.

[13] Grizel H., Héral M., Introduction into France of Japanese oyster (Crassostrea gigas), J. Cons. Perm. Int. Explor. Mer 47 (1991) 399-403.

[14] Gross F., Smyth J.C., The decline of oyster populations, Nature 157 (1946) 540--542.

[15] Guillaud J.F., Les rejets urbains en mer, Hydroécol. Appl. 4 (1992) 159-172.

[16] Héral M., L'ostréiculture française traditionnelle, in : Barnabé G. (éd.), Aquaculture, vol 1, Lavoisier Technique et Documentation, Paris, 1989, pp. 348-397.

[17] Héral M., Approche de la capacité trophique des écosystèmes conchylicoles: synthèse bibliographique, ICES Mar. Sci. Symp. 192 (1991) 48-62.

[18] Imaï T., Numachi K., Oizumi J., Sato S., Studies on the mass mortality of the oyster in Matsushima Bay, II. Search for the cause of mass mortality and possibility to prevent it by transplantation experiment, Bull. Tohoku Reg. Fish. Res. Lab. 25 (1965) 27-38.

[19] Koganazawa A., Present status of studies on the mass mortality of cultural oysters in Japan and its prevention, Proc. 3rd US-Japan Meeting on Aquaculture in Tokyo, Japan, October 15-16 1974, 1975, pp. 29-34.

[20] Laboratoire central d'hydraulique de France (LCHF), Étude sur modèle réduit des phénomènes hydrauliques régissant le bassin ostréicole de Marennes-Oléron, Rap- 
port d'étude LCHF-DDE Charente-maritime, MaisonAlfort, $1975,108 \mathrm{p}$.

[21] Lodato M.I., Mortalité estivale de l'huître creuse, Crassostrea gigas, sur les bancs ostréicoles de Perquis et Ronce (bassin de Marennes-Oléron) : Étude des pratiques culturales et des caractéristiques biologiques et spatiales des élevages, thèse dr. vétérinaire, École nationale vétérinaire de Nantes, $1997,127 \mathrm{p}$.

[22] Lucas A., Remarques sur les rendements de production chez les bivalves marins, Haliotis 12 (1982) 47-66.

[23] Mackin J.G., Mortalities of oysters, Proc. Natl. Shellfish. Assoc. 50 (1961) 40-51.

[24] Mann R., Some biochemical and physiological aspects of growth and gametogenesis in Crassostrea gigas and Ostrea edulis grown at sustained elevated temperatures, J. Mar. Biol. Assoc. UK 59 (1979) 95-110.

[25] Martin J.L., Sornin J.M., Delmas D., El Sayed M., Berthet B., La biodéposition dans les aires ostréicoles. Son rôle dans la concentration de la matière organique et de contaminants potentiels. Son impact sur le sédiment, Ifremer DRV.89.013-RA-Crema-L'Houmeau, $1989,60 \mathrm{p}$.

[26] Maurer D., Comps M., His E., Caractéristiques des mortalités estivales de I'huître Crassostrea gigas dans le bassin d'Arcachon, Haliotis 15 (1986) 309-317.

[27] Ménesguen A., Les problèmes d'eutrophisation littorale et leur modélisation, Hydroécol. Appl. 4 (1992) 55-77.

[28] Ménesguen A., Présentation du phénomène d'eutrophisation littorale, la mer et les rejets urbains, Bendor, France, Ifremer Actes de colloques n ${ }^{\circ} 11,1997$, pp. 35-52.

[29] Mori K., Effects of artificial eutrophisation on the metabolism of the Japanese oyster Crassostrea gigas, Mar. Biol. 53 (1979) $361 \quad 369$.

[30] Nikolic M., Causes of oyster mass mortality, Limski Kanal, Istra, 1960, Acta Adriatica 11 (1964) 227-38.

[31] Perdue J., Beattie J.H., Chew K.K., Some relationship between gametogenic cycle and summer mortality phe- nomenon in the Pacific oyster (Crassostrea gigas) in Washington state, J. Shellfish Res. 1 (1981) 9-16.

[32] Raillard O., Étude des interactions entre les processus physiques et biologiques intervenant dans la production de l'huître Crassostrea gigas (Thunberg) du bassin de Marennes-Oléron : essai de modélisation, thèse $\mathrm{dr}$, univ. Paris-VI, Paris, 1991, 212 p.

[33] Razet D., Faury N., Geairon P., Soletchnik P., Goulletquer P., Les notes techniques de l'unité de recherche aquacole Poitou-Charentes, Ifremer DRV-96.011-La Tremblade, 1996, $40 \mathrm{p}$.

[34] Sauriau P.G., Les mollusques benthiques dans le bassin de Marennes-Oléron : estimation et cartographie des stocks non cultivés, compétition spatiale et trophique, dynamique des populations de Cerastoderma edule (L.), thèse dr., université de Bretagne occidentale, Brest, $1992,309 \mathrm{p}$.

[35] Sinderman C.J., Oyster mortalities and their control, in : Pillay T.V.R., Dill W.M. (Eds.), Advances in Aquaculture, Fishing News Brooks Farnham, England, 1976, pp. 349-361.

[36] Soletchnik P., Razet D., Geairon P., Faury N., Goulletquer P., Écophysiologie de la maturation sexuelle et de la ponte de l'huître creuse Crassostrea gigas: réponses métaboliques (respiration) et alimentaires (filtration, absorption) en fonction des différents stades de maturation, Aquat. Living Resour. 10 (1997) 177-185.

[37] Soletchnik P., Faury N., Razet D., Goulletquer P., Hydrobiology of the Marennes-Oléron bay. Seasonal indices and analysis of trends from 1978 to 1995 , Hydrobiologia 386 (1998) 131-146.

[38] Somin J.M., Feuillet M., Héral M., Deslous-Paoli J.M., Effet des biodépôts de l'huître Crassostrea gigas (Thunberg) sur l'accumulation de matières organiques dans les parcs du bassin de Marennes-Oléron, J. Moll. Stud. 2A (Suppl. 1) (1983) 185-197.

[39] Ventilla R.F., Recent developments in the Japanese oyster culture industry, Adv. Mar. Biol. 21 (1984) 2-54. 